\title{
Changes of microorganism composition in fresh and stored bee pollen from Southern Germany
}

\author{
Carolin Friedle $^{1,2}$ (D) $\cdot$ Paul D'Alvise $^{2} \cdot$ Karsten Schweikert $^{3} \cdot$ Klaus Wallner $^{1} \cdot$ Martin Hasselmann $^{2}$
}

Received: 22 December 2020 / Accepted: 9 April 2021 / Published online: 23 April 2021

(C) The Author(s) 2021, corrected publication 2021

\begin{abstract}
Analysis of plant pollen can provide valuable insights into the existing spectrum of microorganisms in the environment. When harvesting bee-collected pollen as a dietary supplement for human consumption, timely preservation of the freshly collected pollen is fundamental for product quality. Environmental microorganisms contained in freshly collected pollen can lead to spoilage by degradation of pollen components. In this study, freshly collected bee pollen was sampled at different locations and stored under various storage conditions to examine the hypothesis that storage conditions may have an effect on the composition of microorganisms in pollen samples. The samples were analyzed using $16 \mathrm{~S}$ and $18 \mathrm{~S}$ amplicon sequencing and characterized by palynological analysis. Interestingly, the bacterial communities between pollen samples from different locations varied only slightly, whereas for fungal community compositions, this effect was substantially increased. Further, we noticed that fungal communities in pollen are particularly sensitive to storage conditions. The fungal genera proportion Cladosporium and Mycosphaerella decreased, while Zygosaccharomyces and Aspergillus increased during storage. Aspergillus and Zygosaccharomyces fractions increased during storage at $30^{\circ} \mathrm{C}$, which could negatively impact the pollen quality if it is used as a dietary supplement.
\end{abstract}

Keywords Microorganism composition $\cdot$ Bee pollen $\cdot$ Pollen quality $\cdot$ Pollen spoilage

\section{Introduction}

The existing spectrum of microorganisms in the environment can be revealed in pollen samples from plants (Anderson et al. 2013; Manirajan et al. 2019). Pollen, the male gametophyte of gymnosperms and angiosperms, represents the main protein and lipid source for honey bees (Apis mellifera). It provides a full spectrum of not only nutrients, mainly amino acids and lipids, but also carbohydrates, minerals, vitamins, and enzymes (Feás et al. 2012; Pascoal et al. 2014; Avni et al.

Responsible editor: Diane Purchase

Carolin Friedle

carolin_friedle@uni-hohenheim.de

1 Apicultural State Institute, University of Hohenheim, Stuttgart, Germany

2 Institute of Animal Science, Department of Livestock Population Genomics, University of Hohenheim, Stuttgart, Germany

3 Core Facility Hohenheim and Institute of Economics, University of Hohenheim, Stuttgart, Germany
2014; Kostić et al. 2015). Bee-collected pollen consists of pollen grains from flowering plants (including bushes and trees), as well as nectar and salivary secretion from the bees. It is collected by foraging honey bees and transported to the hive in the pollen baskets known as corbicula on their hind legs (Kevan and Baker 1983; Willmer 2011). After storage and microbe-mediated maturation in honeycomb cells, pollen is called "bee bread" and is consumed by nurse bees to produce protein-rich larval food supported by secretions of specialized glands (Lindauer 1952; Cridge et al. 2015). Bee pollen is perceived as a useful dietary supplement for humans, as it provides many necessary nutrients, especially a high amount of protein $( \pm 20 \%)$ including essential amino acids like leucine, isoleucine, and valine, depending on the botanical origin (Paramás et al. 2005; Carpes et al. 2009; Martins et al. 2011; Feás et al. 2012; Nicolson and Human 2013; Taha et al. 2019).

The nutrient composition and microbiological quality of bee pollen depend strongly on its geographic and botanical origin, the weather at the time of collection, as well as on the post-harvest processing procedure by the bee keeper (Hani et al. 2012; Nogueira et al. 2012; Corby-Harris et al. 2014; De-Melo et al. 2015, 2016; Dinkov 2016; 
Disayathanoowat et al. 2020). When gathering of the pollen is not followed by drying or another processing step, growth of microorganisms can compromise pollen quality, leading to negative side effects like fermentation or mycotoxin production (González et al. 2005; Hani et al. 2012; FatrcováSramková et al. 2016). The taxonomical identity of the identified microorganisms in fresh bee pollen suggests that the initial microbial community composition is rather arbitrary and may change in composition to more opportunistic microorganisms with unwanted characteristics that grow well under warm storage conditions (González et al. 2005; Hani et al. 2012). Following the hypothesis that storage conditions may impact the composition of microorganisms, resulting in the spoilage of pollen, we measured the differences in the microorganism composition of freshly harvested bee pollen and compared it with the same pollen after storage under different temperature treatments. This experimental approach aimed to identify the most relevant microorganisms that cause spoilage and identify the most favorable storage condition for preserving pollen quality during and after the harvest.

Previous studies have used cultivation-dependent methods, e.g., bacterial and fungal colony counts on agar plates (Bonvehí and Jordà 1997; González et al. 2005; Estevinho et al. 2012; Feás et al. 2012; Bárbara et al. 2015; De-Melo et al. 2015; Dinkov 2018), and cultivation-independent methods, such as 16S-rRNA amplicon sequencing to characterize the microbial composition in fresh, dried of frozen bee pollen to evaluate the risk of microbial hazards (Anderson et al. 2014; Corby-Harris et al. 2014; Mauriello et al. 2017; Moreno Andrade et al. 2018).

Recently, Disayathanoowat et al. (2020) analyzed the abundances of bacterial and fungal communities in fresh bee pollen and in "bee bread" that was stored for $72 \mathrm{~h}$ within the hive using amplicon sequencing and plate counting. They showed that abundance of bacteria was declining, while the fungal population remained at stable numbers during in-hive storage. However, to our knowledge, there is no information available about changes in bacterial and fungal communities in pollen being stored outside of the hive under defined conditions. Furthermore, taxonomic information about changes in the microbial communities of stored pollen are missing. Consequently, the present study was designed to assess the qualitative changes by next-generation sequencing of $16 \mathrm{~S}$ and 18S PCR-amplicons in the microbial communities of pollen. Samples were stored under different conditions, to simulate how the composition of the microorganisms can be affected by wrong processing or non-harvesting of pollen.

\section{Materials and methods}

Sampling Bee pollen was collected on 1 day in the month of June in 2 consecutive years at three different locations: Baden-
Wuerttemberg, Southern Germany (Hohenheim in $2018(\mathrm{H})$, Forbach in $2019(\mathrm{~F})$, and Nuertingen in $2019(\mathrm{~N})$ ) (Figure S1). To minimize the presence of any potential microorganism on the pollen traps before, the traps were cleaned intensively with $70 \%$ ethanol and installed in front of one hive per site to collect pollen loads from returning honey bees (Apis mellifera) (Detroy and Harp 1976). The freshly collected pollen was divided at the same day of collection and allocated to four different groups "fresh," "cold," "room temperature," and "warm." Condition "cold" simulated a storage in the refrigerator and "room temperature" a storage without refrigeration after harvesting. The condition "warm" simulated unharvested pollen in the trap or pollen was left on environmental conditions of a hot summer day. The samples representing each group were further divided into triplicate samples of $3 \mathrm{~g}$ and filled into $2 \mathrm{~mL}$ tubes (VWR International, Bruchsal, Germany). Group "fresh" was stored immediately at $-80^{\circ} \mathrm{C}$ until extraction, while the other groups were incubated at different temperatures for 7 days $(168 \mathrm{~h})$ and thereafter stored at $-80^{\circ} \mathrm{C}$ until extraction. Group "cold" was incubated at cold temperatures $\left(4^{\circ} \mathrm{C}\right)$, group "room temperature" was incubated at $25^{\circ} \mathrm{C}$, and group "warm" was incubated at $30^{\circ} \mathrm{C}$ and $75 \%$ humidity (humidity was adjusted with a saturated sodium chloride solution). All samples were incubated with open lids in humidity chambers (Figure S2) and samples of the groups "warm" and "room temperature" were further incubated in a warming cabinet (Binder, Tuttlingen, Germany) and samples of group "cold" were placed in a refrigerator (Siemens, Munich, Germany).

Pollen samples in Hohenheim were collected directly by the authors; samples from Forbach and Nuertingen were collected with the help of voluntary beekeepers. All samples were received from privately owned bee colonies, so no exact grid references are given, and no permits were needed for this study.

Palynological analysis A palynological analysis of all pooled samples of each location was performed. All pollen samples were mechanically homogenized by using a mortar, followed by weighing $100 \mathrm{mg}$ homogenized pollen in a $50-\mathrm{mL}$ tube (Buddeberg, Mannheim, Germany) containing $10 \mathrm{~mL}$ demineralized water and a drop of dish soap (Friedle et al. 2021). For each sample, 500 pollen grains were determined. Pollen morphology was identified using a light microscope $(10 \times 40$; VWR International, Bruchsal, Germany).

DNA extraction To analyze the microbial community, DNA was extracted from all 36 bee pollen samples using a TRIzol protocol (D'Alvise et al. 2018; Seeburger et al. 2020). An aliquot of $50 \mathrm{mg}$ pollen was weighted in to a $2 \mathrm{~mL}$ lysis tube with $50 \mu \mathrm{L} 0.1 \mathrm{~mm}$ glass/zirconia beads and $500 \mu \mathrm{L}$ TRIzol (Invitrogen, ThermoFisher Scientific, Schwerte, Germany). The samples were homogenized in a bead beater (FastPrep- 
Table 1 Classification of pollen diversity in the samples

\begin{tabular}{llll}
\hline Classification & Hohenheim 2018 & Forbach 2019 & Nuertingen 2019 \\
\hline Aceraceae_Acer & - & $42 \%$ & - \\
Boraginaceae_Phacelia & $19 \%$ & - & - \\
Brassicaceae_Sinapis-T & $10 \%$ & - & - \\
Malvaceae_Tilia & $8 \%$ & - & $8 \%$ \\
Oleaceae_Ligustrum & - & $0.2 \%$ & $16 \%$ \\
Plantaginaceae_Plantago & $14 \%$ & $3 \%$ & $5 \%$ \\
Ranunculaceae & - & $12 \%$ & - \\
Rosaceae_Aruncus dioicus & - & $0.4 \%$ & $42 \%$ \\
Rosaceae_Filipendula & $10 \%$ & - & $2 \%$ \\
Sapindacaea_Aesculus & $0.4 \%$ & $10 \%$ & - \\
Others & $38 \%$ & $33 \%$ & $28 \%$ \\
\hline
\end{tabular}

24, MP Biomedicals, Eschwege, Germany) at $5.5 \mathrm{~ms}^{-1}$ for $50 \mathrm{~s}$ and incubated for $5 \mathrm{~min}$ at room temperature (RT). After adding $100 \mu \mathrm{L}$ chloroform, shaking for $15 \mathrm{~s}$, and further incubation for $5 \mathrm{~min}$ at RT, two phases were separated by $15 \mathrm{~min}$ centrifugation at $12,000 \times \mathrm{g}$ and $4{ }^{\circ} \mathrm{C}$. The aqueous phase was transferred to another tube for RNA extraction, which can be used for further experiments. To the other phase, $250 \mu \mathrm{L}$ back extraction buffer (4 M guanidine thio-cyanate, $50 \mathrm{mM}$ sodium citrate, $1 \mathrm{M}$ TRIS) were added and extracted by shaking for $15 \mathrm{~s}$. After $10 \mathrm{~min}$ incubation at RT and centrifugation (as before), the aqueous supernatant was transferred to a new tube and precipitated by mixing with $200 \mu \mathrm{L}$ isopropanol, followed by centrifugation (as before). The supernatant was discarded, and $500 \mu \mathrm{L} \mathrm{75 \%}$ ethanol were added to wash the sediment. After short centrifugation $(5 \mathrm{~min}$; $2000 \times g ; 4{ }^{\circ} \mathrm{C}$ ), the supernatant was removed and the sediment dried for $10 \mathrm{~min}$ at RT. An aliquot of $50 \mu \mathrm{L} 8 \mathrm{mM} \mathrm{NaOH}$ were added to redissolve the sediment and the solution was centrifuged for $10 \mathrm{~min}$ at $12,000 \times \mathrm{g}$ at RT to remove membrane lipids. The supernatant was transferred to a new tube and mixed with $4.25 \mu \mathrm{L} 0.1 \mathrm{M}$ HEPES and $0.5 \mu \mathrm{L}$ RNAse A (10 $\mathrm{mg} \mathrm{ml}^{-1}$ Amresco). The DNA extracts were then incubated for $1 \mathrm{~h}$ at $37{ }^{\circ} \mathrm{C}$ and stored at $-20{ }^{\circ} \mathrm{C}$ until analysis. The DNA concentrations were determined using Qubit fluorometer (Thermo Fisher Scientific, Schwerte, Germany) and showed concentrations $<1 \mathrm{ng} / \mu \mathrm{L}$. Some of the DNA extracts requiring additional purification were thereafter precipitated with absolute ethanol; $\mathrm{pH}$ was adjusted to 5.5 with $5 \mu \mathrm{L}$ $3 \mathrm{M}$ sodium acetate solution, then the sample was mixed with $125 \mu \mathrm{L}$ cold ethanol (absolute). After incubation (15 min at 4 ${ }^{\circ} \mathrm{C}$ ) and centrifugation (20 $\left.\mathrm{min} ; 17,000 \times \mathrm{g} ; 4{ }^{\circ} \mathrm{C}\right)$, the supernatant was removed, the sediment was dried for 5 min at RT and dissolved in $20 \mu \mathrm{L}$ nuclease-free water.

PCR and amplicon sequencing Amplicons (using a volume of $10 \mu \mathrm{L}$ in a $20 \mathrm{ng}$ template) of the $\mathrm{V} 3-\mathrm{V} 4$ region in the bacterial 16S-rRNA-gene and amplicons of the ITS1 region in the fungal 18S-rRNA-gene were generated and Illuminasequenced in 2018 by Eurofins Genomics (Ebersberg, Germany) ("Dataset 1"). The PCR conditions followed by library preparation and sequencing were described previously (D'Alvise et al. 2018). Primers for the V3-V4 region of the 16S-rRNA gene were 5'-TACGGGAGGCAGCAG (F) and 5'-CCAGGGTATCTAATCC (R) (Turner et al. 1999; Kisand and Wikner 2003). Primers for the fungal ITS1 region were 5'-GGAAGTAAAAGTCGTAACAAGG (F) and 5'GCTGCGTTCTTCATCGATGC (R) (White et al. 1990). Amplicons from samples in 2019 were Illumina-sequenced by StarSEQ (Mainz, Germany) ("Dataset 2"). Primers for the V3-V4 region of the 16S-rRNA gene were 5'-CCTA CGGGAGGCAGCAG (F) and 5'-GGACTACNNGGGTA TCTAAT (R) (Klindworth et al. 2013). Primers for the fungal
Table 2 Sequences and OTUs within the raw data and after filtering with IMNGS and QIIME2

\begin{tabular}{|c|c|c|c|c|c|}
\hline & & \multicolumn{2}{|c|}{ Dataset $12018(\mathrm{H})$} & \multicolumn{2}{|c|}{ Dataset $22019(\mathrm{~F}, \mathrm{~N})$} \\
\hline & & Bacteria & Fungi & Bacteria & Fungi \\
\hline \multirow[t]{2}{*}{ Raw data } & Sequences & 164,508 & $1,013,947$ & 108,399 & $2,893,070$ \\
\hline & OTUs & 453 & 1093 & 2215 & 5763 \\
\hline \multirow[t]{2}{*}{ IMNGS/QIIME2 } & OTUs & 56 & 131 & 33 & 1998 \\
\hline & Mean OTUs/sample & 40.2 & 23.2 & 21.8 & 357.7 \\
\hline
\end{tabular}


Table 3 Bacterial phyla composition with bacterial genera calculated with total reads in all samples (Dataset 2)

\begin{tabular}{|c|c|}
\hline Actinobacteria (3\%) & Arthrobacter \\
\hline \multirow[t]{6}{*}{ Bacteroidetes (4\%) } & Apibacter \\
\hline & Bacteroides \\
\hline & Chryseobacterium \\
\hline & Epilithonimonas \\
\hline & Flavobacterium \\
\hline & Pedobacter \\
\hline Cyanobacteria $(0.1 \%)$ & Cyanobium \\
\hline \multirow[t]{4}{*}{ Firmicutes (44\%) } & Fusicatenibacter \\
\hline & Lactobacillus \\
\hline & Lactococcus \\
\hline & Staphylococcus \\
\hline \multirow[t]{26}{*}{ Proteobacteria (48\%) } & Acinetobacter \\
\hline & Actibacterium \\
\hline & Arsenophonus \\
\hline & Batronella \\
\hline & Bradyrhizobium \\
\hline & Carnimonas \\
\hline & Citrobacter \\
\hline & Duganella \\
\hline & Erwinia \\
\hline & Escherichia \\
\hline & Frischella \\
\hline & Gilliamella \\
\hline & Gluconacetobacter \\
\hline & Halotalea \\
\hline & Massilia \\
\hline & Neokomagataea \\
\hline & Pantoea \\
\hline & Pectobacterium \\
\hline & Phaseolibacter \\
\hline & Pseudomonas \\
\hline & Rickettsia \\
\hline & Rosenbergiella \\
\hline & Saccharibacter \\
\hline & Serratia \\
\hline & Snodgrassella \\
\hline & Sphingomonas \\
\hline
\end{tabular}

ITS1 region were 5'-CTTGGTCATTTAGAGGAAGTAA (F) and 5'-GCTGCGTTCTTCATCGATGC (R) (White et al. 1990; Gardes and Bruns 1993), an obviously modified and improved set compared to the one from Eurofins Genomics. For all primer sets, efficacies were reported to be high and evaluated by the standardized procedures of the companies.

The clean sequencing reads from the bacterial 16-rRNAgene, as provided after quality control and trimming by the sequencing company, were analyzed on the IMNGS server platform (Lagkouvardos et al. 2016). Quality filtering showed $\%$ Q30 values of about $90 \%$ of the expected amplicon sizes. Analyses were performed without further trimming using a total abundance threshold of $0.1 \%$, and the reads were binned on a $1 \%$ difference criterium (Edgar 2013; Lagkouvardos et al. 2016). Sequences from the fungal 18S-rRNA-gene were analyzed by StarSEQ using the QIIME2 platform. The taxonomic classification of the representative OTU sequences were controlled and refined by BLAST-searches against reference material in the NCBI database (https://blast.ncbi.nlm.nih.gov).

Statistical analysis Differences in the relative abundances of bacterial and fungal OTUs between locations and treatments were analyzed using an ANOVA-type generalized linear model (GLM). Since the analyzed relative abundances are bounded between zero and one, the data are generated by beta distribution (Ferrari and Cribari-Neto 2004). The model was estimated using the betareg package (Cribari-Neto and Zeileis 2010). To identify significant differences in the microbial communities between the different locations and storage conditions, a single-step multiple comparison test (Tukey's test) was performed. The reported $p$-values were corrected for multiple testing. All statistical analyses were performed using $\mathrm{R}$ version 3.6.2. with a significance level of $p=0.05$.

\section{Results}

\section{Characterization of pollen diversity}

The palynological analysis showed, as expected, differences in pollen diversity at each location sites. At location $\mathrm{H}$, pollen composition showed a high variety with $19 \%$ Phacelia sp., 14\% Plantago sp., 10\% Filipendula sp. and Sinapsis-type. Location N predominantly showed pollen of $42 \%$ Aruncus sp. and $16 \%$ Ligustrum sp., followed by $8 \%$ Tilia sp. Location F was dominated by $42 \%$ Acer sp. followed by $12 \%$ pollen from Ranunculacaea and $10 \%$ Aesculus sp. (Table 1, Table S1).

\section{Quantitative data of amplicon sequencing}

The total bacterial and fungal sequences and the total number of operational taxonomic units (OTUs) from 16S (bacteria) and $18 \mathrm{~S}$ (fungi) before and after IMNGS/QIIME2 analyzing are shown in Table 2. After filtering (>0.1\%) and binning, 38 different bacteria genera and 33 different fungal genera were obtained, and their relative abundances were calculated (Table S2 and Table S3). A cut-off of 10\% was performed for statistical analysis to obtain the most abundant bacteria and fungi (Table S4 and Table S5). 
Fig. 1 Stack bar chart, showing the composition of bacterial (a) and fungal (b) communities of Dataset 2 (F and N 2019) (filtered on minimum of $10 \%$ average) in fresh and stored bee pollen

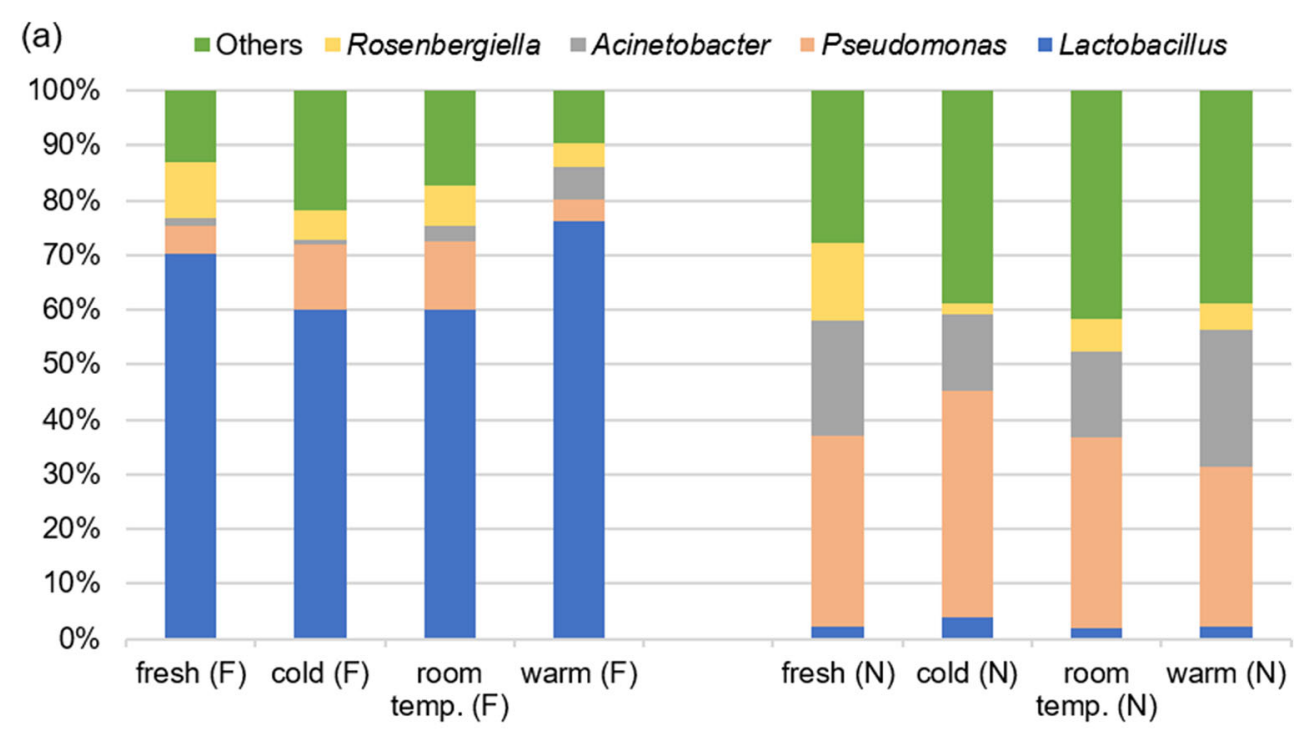

(b)

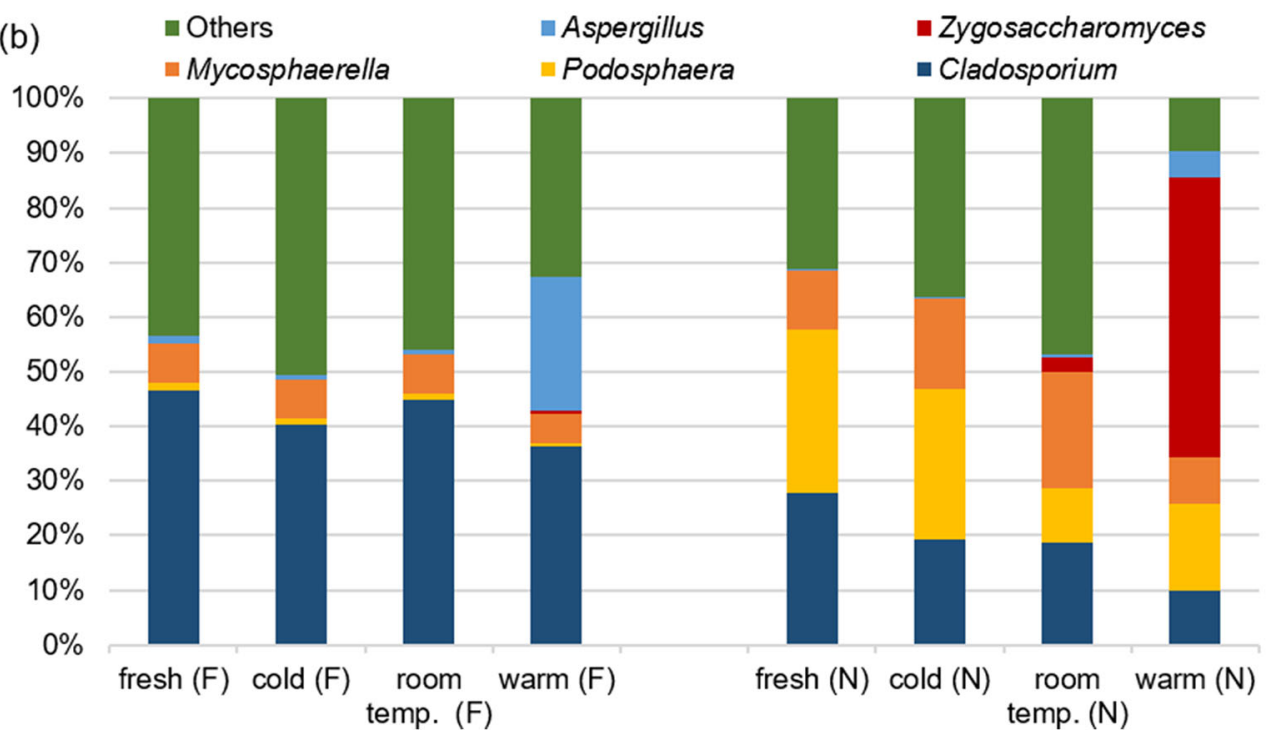

\section{Differences between Dataset 1 and Dataset 2}

Given the fact that for technical reasons the samples of 2018 (Dataset 1, H) and of 2019 (Dataset 2, F and N) were processed by different companies, a stringent comparison between both is not recommended. In particular, we noticed a high deviation in the fungal composition between Dataset 1 and Dataset 2 (Table 2), because primers with different binding specifications were used by the sequencing companies for the fungal ITS1 region. Analyses from Dataset 1 provided only data from Ascomycota, likely as a result of using non-fungispecific primers (see "PCR and amplicon sequencing"). Consequently, the fungal composition from Dataset 1 consists of only three different genera in the samples and probably the full spectrum of fungal diversity in the pollen samples was not revealed in Dataset 1. Therefore, results from Dataset 1 were removed and all subsequent statistical analysis was performed only with Dataset 2 . For the sake of completeness, the results of Dataset 1 are listed additionally in the supplemental material (Table S6, Table S7, and Figure S3).

\section{Microbial diversity in fresh and stored bee pollen}

The most abundant bacterial phyla in all samples were Proteobacteria (48\%) and Firmicutes (44\%), followed by Bacteroidetes (4\%), Actinobacteria (3\%), and Cyanobacteria $(0.1 \%)$ in each of which between one and 26 different bacterial genera have been identified (Table 3). The main bacterial genera in Dataset 2 were Lactobacillus (2-76\%), Pseudomonas (542\%), and Acinetobacter (1-25\%) (Fig. 1a) (Table S4). The percentage of Acinetobacter was higher in pollen after warm storage than in fresh pollen, while Pseudomonas and Rosenbergiella were less abundant after warm storage than in fresh pollen (Fig. 2). However, only a significant difference between storage conditions "room temperature - warm" could be found for Lactobacillus (GLM; $p=0.039$; Tukey; $p=0.043$ ). In 
审 cold 审 fresh 审 room temp 审 warm
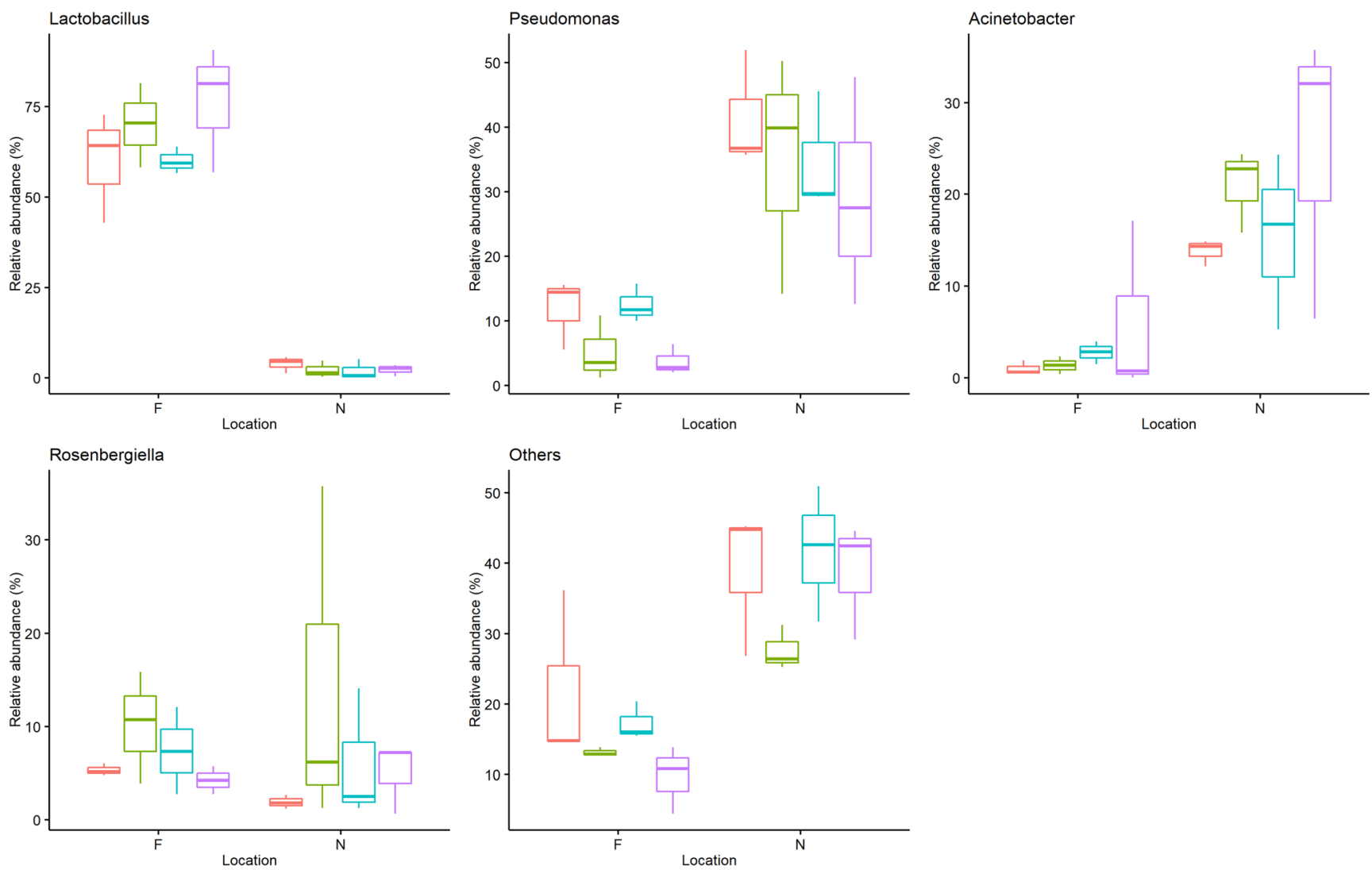

Fig. 2 Box plots chart (created with R 3.6.2), showing that the empirical distribution of bacterial genera differs between locations and storage conditions. The estimated interquartile range is represented as a box and a line spans from the observed minimum to the observed maximum

contrast, the source location of the pollen samples was associated with a significant difference in relative abundance of all bacterial genera (GLM; $p<0.001$ ), except Rosenbergiella (GLM; $p=$ 0.264 ) (Table S6). Location F was characterized by a high proportion of Lactobacillus (60-76\%) and low proportion of Pseudomonas (5-12\%), while location N showed low proportion of Lactobacillus (2-4\%) and high proportion of Pseudomonas (29-42\%) (Fig. 1a).

The fungal phyla from Dataset 2 are composed of $71 \%$ Ascomycota, 21\% Basidiomycota, 0.15\% Motiellellomycota, and unclassified (3.1\%) (Table 4). The phylum Ascomycota consisted of 32 different fungal genera that were found in all samples. The main representatives of the Ascomycota genera in all analyzed samples were Cladosporium (10-45\%), Podosphaera (1-30\%), Mycosphaerella (5-20\%), and Zygosaccharomyces (0-50\%) (Fig. 1b) (Table S5). Significant differences between the storage conditions could be shown for fungal communities (GLM; $p<0.001$ ), except for Podosphaera (GLM; $p=0.084$ ) (Table S8). Zygosaccharomyces and Aspergillus showed significant differences between "fresh - warm," "cold - warm," and "room temperature - warm" conditions (Tukey; $p<0.001$ ) (Table S9), while Cladosporium showed significant differences between "fresh - warm" and "room temperature - warm" conditions (Tukey; $p<0.001$ ). The proportion of Cladosporium under "fresh" and "room temperature" storage conditions was significantly higher than under "warm" conditions (location N), while proportions of Zygosaccharomyces and Aspergillus significantly increased under warm storage conditions in all samples (Fig. 3). Furthermore, all locations showed also significant differences for every fungal genus (GLM; $p<0.001)$.

\section{Discussion}

The microorganism composition in bee pollen is affected by plant source, geographical origin, and bee keeper activities (Nogueira et al. 2012; De-Melo et al. 2016). In this study, we analyzed the botanical origin of the collected bee pollen samples. The pollen composition differed in all pollen samples; therefore, the influence of the botanical origin on the microorganism composition can be supported by the results of this study. We showed as well that the location has a significant influence on the bacterial and fungal communities associated with fresh, bee-collected pollen (GLM; $p<$ 0.001 ). In addition, the composition and the changes of composition of microorganisms are influenced by the 
Table 4 Fungal phyla composition with fungal genera calculated with total reads in all samples (Dataset 2)

\begin{tabular}{ll}
\hline Ascomycota (71\%) & Alpinaria \\
& Alternaria \\
& Aspergillus \\
& Aureobasidium \\
& Bettsia \\
& Blumeria \\
& Cladosporium \\
& Debaryomyces \\
& Didymella \\
& Epicoccum \\
& Erysiphe \\
Fusarium \\
Geosmithia \\
Leptosphaeria \\
Metschnikowia \\
Monilinia \\
Monodictys \\
Mycosphaerella \\
Neodevriesia \\
Neosetophoma \\
Penicillium \\
Periconia \\
Phaeotheca \\
Podosphaera \\
Pseudoophiobolus \\
Pyrenophora \\
Ramularia \\
Septoria \\
Taphrina \\
Tetracladium \\
Trichomerium \\
Zygosaccharomyces \\
\\
\\
\\
M.1\%) \\
\\
\end{tabular}

geographical origin of the pollen samples. However, we only included two different location sites for analysis. In order to support this statement, future studies have to be done with a larger number of samples. Major changes of microorganism composition in bee pollen occurred during storage under simulated "warm" conditions. Therefore, this study confirms our hypothesis that different storage conditions have a significant effect on the composition of microorganisms in pollen. The results demonstrate clearly that pollen has to be removed from the trap and processed immediately to prevent unwanted microorganism growing, instead of leaving pollen in the trap during hot environmental conditions. The results of this study are based on the abundances of sequences; culture-based experiments should also be followed in further studies to support the statements of this study.

Interestingly, the effect of the storage conditions on the microbial communities seems to be different for bacteria and fungi. With regard to the bacterial composition, a significant difference between storage conditions could only be identified for Lactobacillus (GLM; $p=0.039$ ). Lactobacillus, represented by the species Lactobacillus kunkeii, is a core gut bacterium that has been found in all of the analyzed samples and could be detected in earlier studies. It is also present in corbicula pollen, "beebread," and in floral nectar (Anderson et al. 2013; Kwong and Moran 2016). The proportion of Lactobacillus changes significantly between room temperature and warm conditions (Tukey; $p=0.043$ ). Nevertheless, differences between storage conditions could also be determined for other bacteria. Acinetobacter is a bacterium needing aerobic growth condition and has been found not only in different environments, mainly in nectar of plants, but also in corbicula pollen, beebread, and in the intestinal tract of honey bees (Apis mellifera) (Fridman et al. 2012; Kim et al. 2014; Donkersley et al. 2018; Disayathanoowat et al. 2020). A small increase of Acinetobacter was observed during storage in warm conditions. Other studies also showed an increase of Acinetobacter in in-hive stored "bee bread" because it prefers a sugar-rich habitat (Fridman et al. 2012; Disayathanoowat et al. 2020). Two bacterial genera that are commonly found in plant material like nectar are Pseudomonas and Rosenbergiella (Fridman et al. 2012; Halpern et al. 2013). In contrast to fresh pollen, both tended to show a slight decrease during storage under warm conditions. Based on these results, it is reasonable to assume that beside changes in temperature, other factors that might influence the growth of bacteria have to be considered. Previous studies showed that the bacterial population tends to decrease under long-term storage in-hive, related to the low $\mathrm{pH}$ value in the hive (Anderson et al. 2014; Disayathanoowat et al. 2020). Environments with a low $\mathrm{pH}$ value show a high concentration of hydrogen ions, which tends to reduce bacterial growth, whereas the growth of fungi is increased (Rousk et al. 2009).

In contrast to the bacteria, we observed a consistently high influence of the storage conditions on the changes in fungal genus composition (GLM; $p<0.001$ ). The fungus Cladosporium was the most abundant fungus in the freshly collected samples. It is ubiquitously found in indoor and outdoor environments such as air and soil (Zalar et al. 2007). In this study, we showed that the relative fraction of Cladosporium decreases during storage, especially under warm conditions. The fungal genera Podosphaera and Mycosphaerella can be isolated from plant environments and are both known to be plant pathogens (Crous et al. 2006; Baiswar et al. 2010; Garibaldi et al. 2012). Both were identified in freshly collected pollen as well as in stored pollen, but their proportion generally decreased during storage. 
审 cold $\dot{\varphi}$ fresh 官 room temp 审 warm
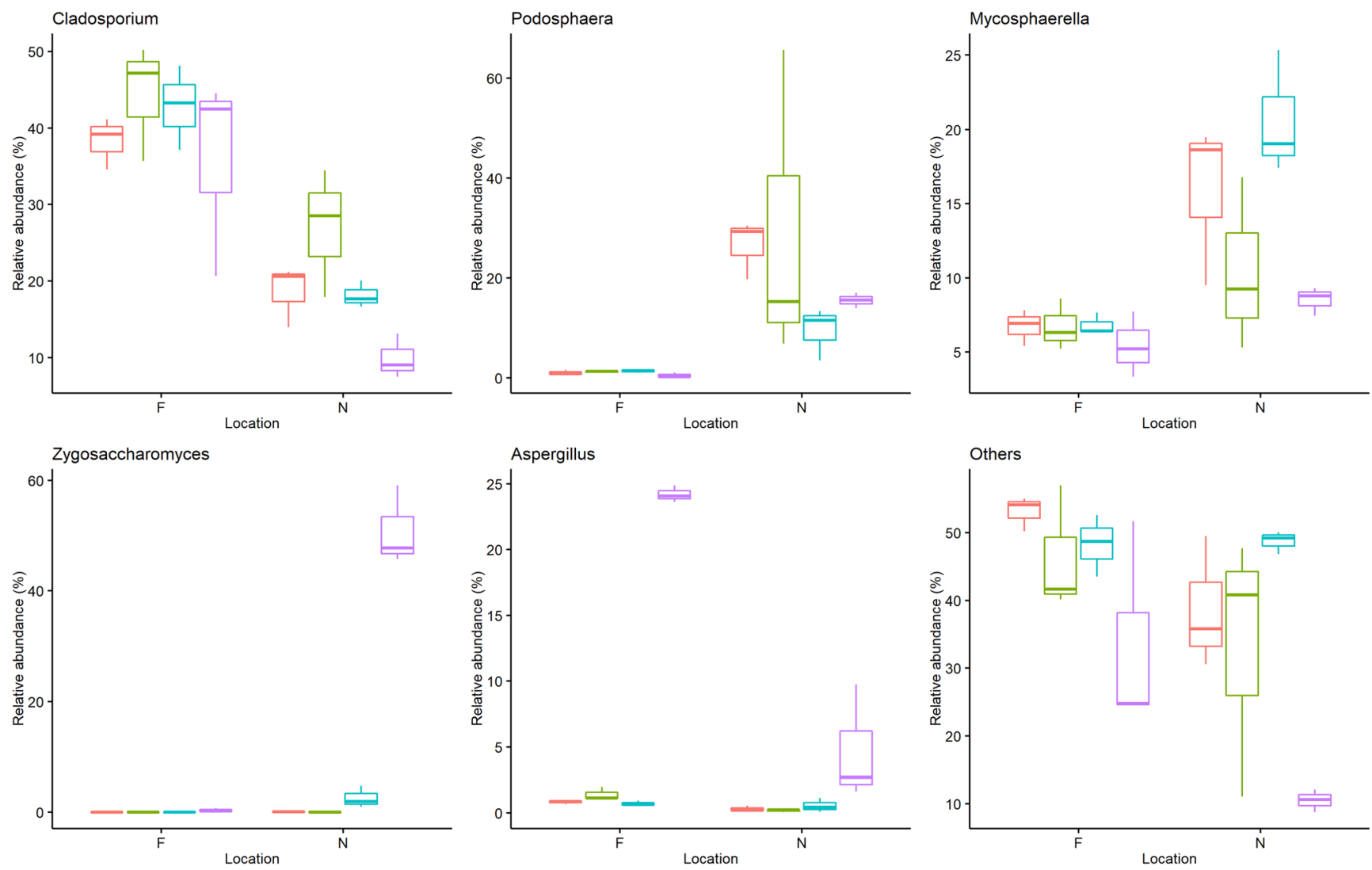

Fig. 3 Box plots chart (created with R 3.6.2), showing that the empirical distribution of fungal genera differs between locations and storage conditions. The estimated interquartile range is represented as a box and a line spans from the observed minimum to the observed maximum

However, several groups of fungi have been identified that grown more strongly under warm and humid storage conditions, especially Zygosaccharomyces and Aspergillus. Previous studies have also shown that fungal composition changes during storage of bee bread (Sinpoo et al. 2017; Detry et al. 2020; Disayathanoowat et al. 2020). Sinpoo et al. (2017) demonstrated that the high diversity of fungal communities in bee bread decreased significantly during storage time. The most dominated fungal species in corbicular pollen were Cladosporium and Aspergillus, whereas also Zygosaccharomyces dominated in stored bee bread. Detry et al. (2020) also showed that the high abundance of yeast decreased within increasing storage time. However, also the yeast Zygosaccharomyces dominated clearly in aged bee bread. The yeast genus Zygosaccharomyces is very osmotolerant yeast species and has a high tolerance for different sugars. Therefore, it is known as notorious spoilage organism of sugar-rich foods and beverages such as candy, fruit juices, sugar syrups, and wine (Martorell et al. 2007; Zuehlke et al. 2013; Aneja et al. 2014; Marvig et al. 2014). Zygosaccharomyces spp. are also normal members of the fungal gut communities of honey bees (Yun et al. 2018); consequently, they can be transmitted from the bee saliva to the pollen. In this study, Zygosaccharomyces spp. was identified as the most prolifically growing microorganisms in bee pollen stored under warm temperatures. Therefore, it seems likely that Zygosaccharomyces can spoil bee pollen in warm and humid storage conditions, as they producing ethanol or carbon dioxide from sugar. Pollen, used as food supplement for human, should not contain any spoilage yeast, otherwise the aroma and sensory can be influenced by fermentation (Sperber and Doyle 2009). However, since the yeast is probably already being transferred from the bees to the pollen, it is very important to prevent their reproduction and growth. The growth of such yeasts can be prevented by freezing or cooling. In our study, we did not observe any increase in the Zygosaccharomyces proportion at $4{ }^{\circ} \mathrm{C}$. Other studies showed as well that Zygosaccharomyces growth is clearly reduced even at $8^{\circ} \mathrm{C}$ (Marvig et al. 2014). Also, an increase in the Aspergillus proportion in the samples stored under warm conditions has to be observed with regard to human nutrition. Aspergillus is extremely halo- and osmotolerant (Stratford et al. 2019) and the genus contains a number of highly mycotoxigenic species (González et al. 2005). Some species of this fungal genus have been identified as pathogens in insects, animals, and humans (Foley et al. 2014; Dagenais and 
Keller 2009). In food, Aspergillus spp. can spoil as visible growth of black mold, discoloration, or in producing mycotoxins. The effects of mycotoxins on human health are complex and can cause cancerogenic effects or central nervous system damage (Sperber and Doyle 2009). Since the growth of Aspergillus can cause major effects on human health, it is particularly important to prevent the growing in pollen samples. Another study reported findings of mycotoxin-producing Aspergillus spp. in "ready-to-eat" pollen samples from Spain (González et al. 2005). The fungal contamination in the study from González et al. indicated that the post-harvest pollen processed negatively impacted pollen quality. Incorrect storage or drying conditions as well as non-daily harvest were pointed out as reasons for the contamination.

In conclusion, pollen stored under warm conditions showed the clearest changes in fungal composition, compared to the freshly collected pollen (Tukey; $p<0.001$ ). Growth of fungi from the genera Zygosaccharomyces or Aspergillus was likely the cause of spoilage. Therefore, during processing of freshly harvested bee pollen, it is important to prevent growth of these spoilage microorganisms. This is most conveniently achieved by harvesting daily, followed by processing the pollen directly to refrigeration or, even better, freezing.

Supplementary Information The online version contains supplementary material available at https://doi.org/10.1007/s11356-021-13932-4.

Acknowledgements The authors thank Dr. Raghdan Alkattea for help with the palynological analysis. Furthermore, the authors thank the volunteer beekeepers for sample collection.

Data Availability of data and materials The authors confirm the data generated or analyzed during this study are included in this published article and its supplementary information files. All datasets (including the raw data and sequences) used and analyzed during this current study are also available from the corresponding author on reasonable request.

Author contribution Carolin Friedle: conceptualization, methodology, data curation, formal analysis, resources, visualization, writing - original draft, and writing — review \& editing; Paul D'Alvise: methodology, data curation, formal analysis, and writing — review \& editing; Karsten Schweikert: data curation, formal analysis, visualization, and writing review \& editing; Klaus Wallner: conceptualization, data curation, funding acquisition, supervision; writing - review \& editing; Martin Hasselmann: conceptualization, methodology, data curation, supervision, and writing - review \& editing.

Funding Open Access funding enabled and organized by Projekt DEAL. This study was supported by the Ministry of Rural Areas and Consumer Protection Baden-Wuerttemberg.

\section{Declarations}

Ethics approval The authors confirm that ethical standards were addressed.
Consent to participate The authors confirm the volunteer's declaration of consent.

Consent to publish The authors confirm the volunteer's consent for publication. The map generated by the Environmental Information System (UIS) of the LUBW State Institute for the Environment BadenWuerttemberg and the State Office for Geoinformation and Rural Development Baden-Wuerttemberg have been given permission to be published by mentioning them as basic data.

Competing interests The authors declare no competing interests.

Open Access This article is licensed under a Creative Commons Attribution 4.0 International License, which permits use, sharing, adaptation, distribution and reproduction in any medium or format, as long as you give appropriate credit to the original author(s) and the source, provide a link to the Creative Commons licence, and indicate if changes were made. The images or other third party material in this article are included in the article's Creative Commons licence, unless indicated otherwise in a credit line to the material. If material is not included in the article's Creative Commons licence and your intended use is not permitted by statutory regulation or exceeds the permitted use, you will need to obtain permission directly from the copyright holder. To view a copy of this licence, visit http://creativecommons.org/licenses/by/4.0/.

\section{References}

Anderson KE, Sheehan TH, Mott BM, Maes P, Snyder L, Schwan MR, Walton A, Jones BM, Corby-Harris V (2013) Microbial ecology of the hive and pollination landscape: bacterial associates from floral nectar, the alimentary tract and stored food of honey bees (Apis mellifera). PLoS One 8(12):e83125. https://doi.org/10.1371/ journal.pone. 0083125

Anderson KE, Carroll MJ, Sheehan T, Lanan MC, Mott BM, Maes P, Corby-Harris V (2014) Hive-stored pollen of honey bees: many lines of evidence are consistent with pollen preservation, not nutrient conversion. Mol Ecol 23(23):5904-5917. https://doi.org/10.1111/ mec. 12966

Aneja KR, Dhiman R, Aggarwal NK, Aneja A (2014) Emerging preservation techniques for controlling spoilage and pathogenic microorganisms in fruit juices. Int J Microbiol 2014(7):1-14. https://doi.org/ $10.1155 / 2014 / 758942$

Avni D, Hendriksma HP, Dag A, Uni Z, Shafir S (2014) Nutritional aspects of honey bee-collected pollen and constraints on colony development in the eastern Mediterranean. J Insect Physiol 69:6573. https://doi.org/10.1016/j.jinsphys.2014.07.001

Baiswar P, Chandra S, Kumar R, Ngachan SV, Munda GC (2010) First report of powdery mildew caused by Podosphaera sp. on Hibiscus sabdariffa in India. Austral Plant Dis Notes 5(1):123. https://doi.org/ 10.1071/DN10045

Bárbara M, Machado C, Sodré G, Dias L, Estevinho L, de Carvalho C (2015) Microbiological assessment, nutritional characterization and phenolic compounds of bee pollen from Mellipona mandacaia Smith, 1983. Molecules 20(7):12525-12544. https://doi.org/10. 3390/molecules200712525

Bonvehí JS, Jordà RE (1997) Nutrient composition and microbiological quality of honeybee-collected pollen in Spain. J Agric Food Chem (45):725-732. https://doi.org/10.1021/jf960265q

Carpes ST, Mourao GB, Alencar SM, Masson ML (2009) Chemical composition and free radical scavenging activity of Apis mellifera bee pollen from Southern Brazil. Braz J Food Technol (03):220 229. https://doi.org/10.4260/BJFT2009800900016 
Corby-Harris V, Maes P, Anderson KE (2014) The bacterial communities associated with honey bee (Apis mellifera) foragers. PLoS One 9(4): e95056. https://doi.org/10.1371/journal.pone.0095056

Cribari-Neto F, Zeileis A (2010) Beta regression in R. J Stat Softw (43). https://doi.org/10.18637/jss.v034.i02

Cridge AG, Leask MP, Duncan EJ, Dearden PK (2015) What do studies of insect polyphenisms tell us about nutritionally-triggered epigenomic changes and their consequences? Nutrients 7(3):17871797. https://doi.org/10.3390/nu7031787

Crous PW, Wingfield MJ, Mansilla JP, Alfenas AC, Groenewald JZ (2006) Phylogenetic reassessment of Mycosphaerella spp. and their anamorphs occurring on Eucalyptus. II. Stud Mycol 55:99-131. https://doi.org/10.3114/sim.55.1.99

D'Alvise P, Böhme F, Codrea MC, Seitz A, Nahnsen S, Binzer M, Rosenkranz P, Hasselmann M (2018) The impact of winter feed type on intestinal microbiota and parasites in honey bees. Apidologie 49(2):252-264. https://doi.org/10.1007/s13592-0170551-1

Dagenais TRT, Keller NP (2009) Pathogenesis of Aspergillus fumigatus in Invasive Aspergillosis. CMR 22(3):447-465. https://doi.org/10. 1128/CMR.00055-08

De-Melo AAM, Estevinho MLMF, Almeida-Muradian LB (2015) A diagnosis of the microbiological quality of dehydrated bee-pollen produced in Brazil. Lett Appl Microbiol 61(5):477-483. https://doi. org/10.1111/lam.12480

De-Melo AAM, Estevinho MLMF, Sattler JAG, Souza BR, Freitas AS, Barth OM, Almeida-Muradian LB (2016) Effect of processing conditions on characteristics of dehydrated bee-pollen and correlation between quality parameters. LWT Food Sci Technol 65:808-815. https://doi.org/10.1016/j.lwt.2015.09.014

Detroy BF, Harp ER (1976) Pollen traps: trapping pollen from honey bee colonies. Agricultural Research Service. United States Department ofAgricultural. Prod Res Rep Madison (163)

Detry R, Simon-Delso N, Bruneau E, Daniel H-M (2020) Specialisation of yeast genera in different phases of bee bread maturation. Microorganisms 8(11). https://doi.org/10.3390/ microorganisms 8111789

Dinkov D (2016) Microorganisms in vacuum stored flower bee pollen. J Bacteriol Virol 46(4):258. https://doi.org/10.4167/jbv.2016.46.4. 258

Dinkov D (2018) Isolation and identification of bacteria in flower bee pollen. Walailak J Sci Tech 15(3):225-234

Disayathanoowat T, Li H, Supapimon N, Suwannarach N, Lumyong S, Chantawannakul P, Guo J (2020) Different dynamics of bacterial and fungal communities in hive-stored bee bread and their possible roles: a case study from two commercial honey bees in China. Microorganisms 8(2). https://doi.org/10.3390/ microorganisms 8020264

Donkersley P, Rhodes G, Pickup RW, Jones KC, Wilson K (2018) Bacterial communities associated with honeybee food stores are correlated with land use. Ecol Evol 8(10):4743-4756. https://doi. org/10.1002/ece3.3999

Edgar RC (2013) UPARSE: highly accurate OTU sequences from microbial amplicon reads. Nat Methods 10(10):996-998. https://doi. org/10.1038/nmeth.2604

Estevinho LM, Rodrigues S, Pereira AP, Feás X (2012) Portuguese bee pollen: palynological study, nutritional and microbiological evaluation. Int J Food Sci Technol 47(2):429-435. https://doi.org/10.1111/ j.1365-2621.2011.02859.x

Fatrcová-Šramková K, Nôžková J, Máriássyová M, Kačániová M (2016) Biologically active antimicrobial and antioxidant substances in the Helianthus annuus L. bee pollen. J Environ Sci Health B 51(3):176181. https://doi.org/10.1080/03601234.2015.1108811

Feás X, Vázquez-Tato MP, Estevinho L, Seijas JA, Iglesias A (2012) Organic bee pollen: botanical origin, nutritional value, bioactive compounds, antioxidant activity and microbiological quality.
Molecules 17(7):8359-8377. https://doi.org/10.3390/ molecules 17078359

Ferrari S, Cribari-Neto F (2004) Beta regression for modelling rates and proportions. J Appl Stat 31(7):799-815. https://doi.org/10.1080/ 0266476042000214501

Foley K, Fazio G, Jensen AB, Hughes WOH (2014) The distribution of Aspergillus spp. opportunistic parasites in hives and their pathogenicity to honey bees. Vet Microbiol 169(3-4):203-210. https://doi. org/10.1016/j.vetmic.2013.11.029

Fridman S, Izhaki I, Gerchman Y, Halpern M (2012) Bacterial communities in floral nectar. Environ Microbiol Rep 4(1):97-104. https:// doi.org/10.1111/j.1758-2229.2011.00309.x

Friedle C, Wallner K, Rosenkranz P, Martens D, Vetter W (2021) Pesticide residues in daily bee pollen samples (April-July) from an intensive agricultural region in Southern Germany. Environ Sci Pollut Res:1-15. https://doi.org/10.1007/s11356-020-12318-2

Gardes M, Bruns TD (1993) ITS primers with enhanced specificity for basidiomycetes: application to the identification of mycorrhizae and rusts. Mol Ecol 2(2):113-118. https://doi.org/10.1111/j.1365-294x. 1993.tb00005.x

Garibaldi A, Bertetti D, Pensa P, Poli A, Gullino ML (2012) Podosphaera sp. on Euphorbia susannae and E. inermis in Italy. Plant Dis 96(12): 1824. https://doi.org/10.1094/PDIS-06-12-0569-PDN

González G, Hinojo MJ, Mateo R, Medina A, Jiménez M (2005) Occurrence of mycotoxin producing fungi in bee pollen. Int $\mathrm{J}$ Food Microbiol 105(1):1-9. https://doi.org/10.1016/j.ijfoodmicro. 2005.05.001

Halpern M, Fridman S, Atamna-Ismaeel N, Izhaki I (2013) Rosenbergiella nectarea gen. nov., sp. nov., in the family Enterobacteriaceae, isolated from floral nectar. Int J Syst Evol Microbiol 63(Pt 11):4259-4265. https://doi.org/10.1099/ijs.0. 052217-0

Hani B, Dalila B, Saliha D, Daoud H, Mouloud G, Seddik K (2012) Microbioligical sanitary aspects of pollen. Adv Environ Biol (6): 1415-1420. ISSN 1995-0756

Kevan PG, Baker HG (1983) Insects as flower visitors and pollinators. Annu Rev Entomol 28(1):407-453. https://doi.org/10.1146/ annurev.en.28.010183.002203

Kim PS, Shin N-R, Kim JY, Yun J-H, Hyun D-W, Bae J-W (2014) Acinetobacter apis sp. nov., isolated from the intestinal tract of a honey bee, Apis mellifera. J Microbiol 52(8):639-645. https://doi. org/10.1007/s12275-014-4078-0

Kisand V, Wikner J (2003) Limited resolution of 16S rDNA DGGE caused by melting properties and closely related DNA sequences. J Microbiol Methods 54(2):183-191. https://doi.org/10.1016/ S0167-7012(03)00038-1

Klindworth A, Pruesse E, Schweer T, Peplies J, Quast C, Horn M, Glöckner FO (2013) Evaluation of general 16S ribosomal RNA gene PCR primers for classical and next-generation sequencingbased diversity studies. Nucleic Acids Res 41(1):e1. https://oi. org/10.1093/nar/gks808

Kostić AŽ, Barać MB, Stanojević SP, Milojković-Opsenica DM, Tešić ŽL, Šikoparija B, Radišić P, Prentović M, Pešić MB (2015) Physicochemical composition and techno-functional properties of bee pollen collected in Serbia. LWT Food Sci Technol 62(1):301309. https://doi.org/10.1016/j.lwt.2015.01.031

Kwong WK, Moran NA (2016) Gut microbial communities of social bees. Nature reviews. Microbiology 14(6):374-384. https://doi. org/10.1038/nrmicro.2016.43

Lagkouvardos I, Joseph D, Kapfhammer M, Giritli S, Horn M, Haller D, Clavel T (2016) IMNGS: a comprehensive open resource of processed 16S rRNA microbial profiles for ecology and diversity studies. Sci Rep 6:33721. https://doi.org/10.1038/srep33721

Lindauer M (1952) A contribution to the question of the division of labor in the bee state. (Ein Beitrag zur Frage der Arbeitsteilung im 
Bienenstaat). Z Vergl Physiol 34(4):299-345. https://doi.org/10. 1007/BF00298048

Manirajan BA, Ratering S, Cardinale M, Maisinger C, Schnell S (2019) The microbiome of flower pollen and its potential impact on pollenrelated allergies. The flowering of plant microbiome and the human connection. Institute of Applied Microbiology, Justus-Liebig University, Giessen, Germany

Martins MCT, Morgano MA, Vicente E, Baggio SR, Rodriguez-Amaya DB (2011) Physicochemical composition of bee pollen from eleven Brazilian States. J Agric Sci (55):107-116. ISSN 1643-4439

Martorell P, Stratford M, Steels H, Fernández-Espinar MT, Querol A (2007) Physiological characterization of spoilage strains of Zygosaccharomyces bailii and Zygosaccharomyces rouxii isolated from high sugar environments. Int J Food Microbiol 114(2):234 242. https://doi.org/10.1016/j.ijfoodmicro.2006.09.014

Marvig CL, Kristiansen RM, Madsen MG, Nielsen DS (2014) Identification and characterisation of organisms associated with chocolate pralines and sugar syrups used for their production. Int $\mathrm{J}$ Food Microbiol 185:167-176. https://doi.org/10.1016/j. ijfoodmicro.2014.05.017

Mauriello G, de Prisco A, Di Prisco G, La Storia A, Caprio E (2017) Microbial characterization of bee pollen from the Vesuvius area collected by using three different traps. PLoS One 12(9): e0183208. https://doi.org/10.1371/journal.pone.0183208

Moreno Andrade VD, Saldaña Gutiérrez C, Calvillo Medina RP, Cruz Hérnandez A, Vázquez Cruz MA, Torres Ruíz A, Romero Gómez S, Ramos López MA, Álvarez-Hidalgo E, López-Gaytan SB, Ramírez NS, Jones GH, Hernandez-Flores JL, Campos-Guillén J (2018) Microbial diversity in commercial bee pollen from Europe, Chile, and Mexico, based on 16S rRNA gene amplicon metagenome sequencing. Genome Announc 6(20). https://doi.org/10.1128/ genomeA.00247-18

Nicolson SW, Human H (2013) Chemical composition of the 'low quality' pollen of sunflower (Helianthus annuus, Asteraceae). Apidologie 44(2):144-152. https://doi.org/10.1007/s13592-0120166-5

Nogueira C, Iglesias A, Feás X, Estevinho LM (2012) Commercial bee pollen with different geographical origins: a comprehensive approach. Int J Mol Sci 13(9):11173-11187. https://doi.org/10.3390/ ijms130911173

Paramás AMG, Bárez JAG, Marcos CC, García-Villanova RJ, Sánchez JS (2005) HPLC-fluorimetric method for analysis of amino acids in products of the hive (honey and bee-pollen). Food Chem 95(1):148156. https://doi.org/10.1016/j.foodchem.2005.02.008

Pascoal A, Rodrigues S, Teixeira A, Feás X, Estevinho LM (2014) Biological activities of commercial bee pollens: antimicrobial, antimutagenic, antioxidant and anti-inflammatory. Food Chem Toxicol 63:233-239. https://doi.org/10.1016/j.fct.2013.11.010
Rousk J, Brookes PC, Bååth E (2009) Contrasting soil pH effects on fungal and bacterial growth suggest functional redundancy in carbon mineralization. Appl Environ Microbiol 75(6):1589-1596. https:// doi.org/10.1128/AEM.02775-08

Seeburger VC, D'Alvise P, Shaaban B, Schweikert K, Lohaus G, Schroeder A, Hasselmann M (2020) The trisaccharide melezitose impacts honey bees and their intestinal microbiota. PLoS One 15(4):e0230871. https://doi.org/10.1371/journal.pone.0230871

Sinpoo C, Williams GR, Chantawannakul P (2017) Dynamicy of fungal communities in corbicular pollen and bee bread. Chiang Mai J Sci 44(4):1235-1247

Sperber WH, Doyle MP (2009) Compendium of the microbiological spoilage of foods and beverages. Springer New York, New York

Stratford M, Steels H, Novodvorska M, Archer DB, Avery SV (2019) Extreme osmotolerance and halotolerance in food-relevant yeasts and the role of glycerol-dependent cell individuality. Front Microbiol 9:2179. https://doi.org/10.3389/fmicb.2018.03238

Taha E-KA, Al-Kahtani S, Taha R (2019) Protein content and amino acids composition of bee-pollens from major floral sources in AlAhsa, eastern Saudi Arabia. Saudi J Biol Sci 26(2):232-237. https:// doi.org/10.1016/j.sjbs.2017.06.003

Turner S, Pryer KM, Miao Vivian PW, Palmer JD (1999) Investigating deep phylogenetic relationships among cyanobacteria and plastids by small subunit rRNA sequence analysis. J Eukaryot Microbiol 46: 327-338

White TJ, Bruns TD, Lee SB, Taylor JW (1990) Amplification and direct sequencing of fungal ribosomal RNA Genes for phylogenetics. Evolution PCR Protocols: A Guide to Methods and Applications: $315-322$

Willmer P (2011) Pollination and floral ecology. Princeton University Press, New Jersey

Yun J-H, Jung M-J, Kim PS, Bae J-W (2018) Social status shapes the bacterial and fungal gut communities of the honey bee. Sci Rep 8(1): 2019. https://doi.org/10.1038/s41598-018-19860-7

Zalar P, de Hoog GS, Schroers H-J, Crous PW, Groenewald JZ, GundeCimerman N (2007) Phylogeny and ecology of the ubiquitous saprobe Cladosporium sphaerospermum, with descriptions of seven new species from hypersaline environments. Stud Mycol 58:157183. https://doi.org/10.3114/sim.2007.58.06

Zuehlke JM, Petrova B, Edwards CG (2013) Advances in the control of wine spoilage by Zygosaccharomyces and Dekkera/Brettanomyces. Annu Rev Food Sci Technol 4(1):57-78. https://doi.org/10.1146/ ANNUREV-FOOD-030212-182533

Publisher's note Springer Nature remains neutral with regard to jurisdictional claims in published maps and institutional affiliations. 